\title{
NÍVEL DE DISCLOSURE E FORMA DE APRESENTAÇÃO DAS NOTAS EXPLICATIVAS: UM ESTUDO À LUZ DA OCPC 07
}

\author{
Régis Barroso Silva ${ }^{1}$ \\ Lívia Arruda Castro 2 \\ Sylvia Rejane Magalhães Domingos 3 \\ Vera Maria Rodrigues Ponte ${ }^{4}$
}

- Artigo recebido em: 28/03/2019 -- Artigo aceito em: 12/07/2020 -." Segunda versão aceita em: 17/08/2020

\section{RESUMO}

Este estudo investigou a relação entre o nível de disclosure e a forma de apresentação das notas explicativas nas companhias brasileiras, considerando as recomendações contidas na OCPC 07. O disclosure foi calculado por meio de dois índices propostos por Santos, Ponte e Mapurunga (2014) e posteriormente replicados nos estudos de Silva (2017) e Umbelino, Ponte, Silvia e Lima (2019). A forma de apresentação das notas explicativas foi analisada com base no tamanho, na legibilidade e na similaridade dos documentos. Ademais, a pesquisa adotou o lançamento da OCPC 07 como marco comparativo entre - período anterior (2010-2013) e posterior (2014-2017) à publicação da orientação. Os resultados indicaram que apenas a legibilidade desses documentos melhorou após o lançamento da OCPC 07 e que a similaridade entre os documentos passou a ser maior, o que contraria as disposições da orientação. Constatou-se também a existência de associação entre a forma de apresentação das notas explicativas e o nível de divulgação. Além disso, identificou-se que o tamanho, a legibilidade e a similaridade explicam

\footnotetext{
1 Mestre do Programa de Pós-Graduação em Administração e Controladoria, Centro Universitário Christus - Unichristus. Endereço: Rua João Adolfo Gurgel, nº 133 - Bairro Cocó Fortaleza - Ceará, Brasil. Telefone: (85) 3265-8100. E-mail: regis.silva@alu.ufc.br http://orcid.org/0000-0002-3749-6199
}

2 Doutoranda do Programa de Pós-Graduação em Administração e Controladoria, Universidade Federal do Ceará, Programa de Pós-Graduação em Administração e Controladoria. Endereço: Avenida da Universidade, $n^{\circ} 2481$ - Bairro Benfica - Fortaleza Ceará, Brasil. Telefone: (85) 3366-7827. E-mail: liviacastro@gmail.com

https://orcid.org/0000-0002-2166-1145

3 Doutoranda do Programa de Pós-Graduação em Administração e Controladoria, Universidade Federal do Ceará - UFC, Programa de Pós-Graduação em Administração e Controladoria Endereço: Avenida da Universidade, n' 2481 - Bairro Benfica - Fortaleza Ceará, Brasil. Telefone: (85) 3366-7827. E-mail: sylvia_rejane@hotmail.com

https://orcid.org/0000-0002-8112-0148

4 Doutora em Ciências Contábeis pela Universidade de São Paulo, Universidade Federal do Ceará - UFC, Programa de Pós-Graduação em Administração e Controladoria. Endereço: Avenida da Universidade, $\mathrm{n}^{\circ} 2481$ - Bairro Benfica - Fortaleza - Ceará, Brasil. Telefone: (85) 3366-7827. E-mail: vponte@fortalnet.com.br

https://orcid.org/0000-0003-4910-9720

Editor responsável pela aprovação do artigo: Dr. João Estevão Barbosa Neto Editora responsável pela edição do artigo: Dr ${ }^{a}$. Bruna Camargos Avelino 
positivamente o disclosure. Assim, pode-se concluir que, no grupo de empresas analisadas, os mais altos índices de divulgação estão atrelados àquelas com notas explicativas mais extensas, assim como a documentos com baixa legibilidade e também aos que apresentam estruturas mais similares entre si.

Palavras-chave: OCPC 07. Disclosure. Notas Explicativas.

\title{
LEVEL OF DISCLOSURE AND PRESENTATION FORM OF COMPANIES' NOTES: A STUDY IN THE LIGHT OF OCPC 07
}

\begin{abstract}
This study investigated the relationship between the level of disclosure and the presentation form of Brazilian companies' Notes, considering the recommendations contained in OCPC 07. Disclosure was calculated using two indexes proposed by Santos, Ponte and Mapurunga (2014) and later replicated in the studies by Silva (2017) and Umbelino, Ponte, Silva e Lima (2019). The presentation form of the companies' Notes was analyzed based on the size, legibility and similarity of the documents. In addition, the research adopted the launch of OCPC 07 as a comparative framework between the period before (2010-2013) and after (2014-2017) the publication of the guidance. The results indicated that only the readability of these documents improved after the launch of OCPC 07 and that the similarity between the documents became greater, which goes against the provisions of the guidance. It was also found that there was an association between the presentation form of the companies' Notes and the level of disclosure. In addition, it was found that size, legibility and similarity positively explain disclosure. Thus, it can be concluded that, in the group of companies analyzed, the highest disclosure rates are linked to those with more extensive companies' Notes, as well as to documents with low legibility and also to those that have more similar structures to each other.
\end{abstract}

Keywords: OCPC 07, Disclosure, Companies' Notes

\section{INTRODUÇÃO}

A assimetria informacional entre os controladores e usuários externos da companhia cria a demanda para o disclosure corporativo, que é o canal de transmissão das informações da empresa para o mercado (Murcia, 2009). Nesse contexto, as demonstrações contábeis despontam como a principal fonte de comunicação financeira entre as entidades e seus usuários, auxiliando seu processo decisório, razão pela qual, portanto, devem oferecer de forma sintetizada a melhor compreensão acerca dos fatos organizacionais (Takamatsu, Lamounier, \& Colauto, 2008).

Após a convergência das normas contábeis brasileiras para as Normas Internacionais de Relatórios Financeiros (International Financial Reporting Standards - IFRS), uma série de padrões contábeis foi editada, refletindo em melhoria das informações contábeis evidenciadas, como destacam Barth, 
Landsman e Lang (2008), Coelho, Niyama e Rodrigues (2011), Hellman (2008), Klann e Beuren (2011) e Lima (2007).

A convergência das normas contábeis brasileiras para o padrão internacional teve início em 2007, seguindo-se a aplicação gradual dos novos padrões contábeis, até a completa adoção em 2010. Apesar de essa adesão ter contribuído para aumentar a qualidade informacional das companhias, foi constatado um aumento significativo da extensão das notas explicativas, não só no Brasil, como também em outros países que passaram a adotar as IFRS, demonstrando um excesso de dados não necessariamente relevantes, assim como a ausência de foco do conteúdo divulgado (Martins, Oliveira, Niyama, \& Diniz, 2014).

Guay, Samuels e Taylor (2016) explicam que o aumento desse volume de informações deveu-se à complexidade das regras e princípios contábeis estabelecidos pelas IFRS, o que exigiu uma linguagem explicativa em torno das demonstrações contábeis. Por se tratar de um padrão contábil embasado muito mais em princípios do que em regras, as normas internacionais de contabilidade exigiram maior grau de julgamento dos responsáveis pela elaboração das demonstrações contábeis, o que, por sua vez, resultou em uma divulgação mais detalhada dos princípios, políticas e critérios de estimativas adotados pelas companhias.

Por outro lado, Plumlee, Brown, Hayes e Marshall (2015) argumentam que o aumento da extensão da informação divulgada não necessariamente implica mais qualidade informacional. Os autores destacam que, em particular, os investidores e analistas financeiros criticam uma sobrecarga de informações percebida a partir de divulgações financeiras sem o correspondente aumento de sua qualidade, indicando que um maior volume de divulgação não necessariamente corresponde a uma maior qualidade dos relatórios contábeis, sobretudo das notas explicativas.

Assim, foram apresentados alguns aspectos relativos à forma de apresentação das notas explicativas, no que tange ao tamanho, à legibilidade e à similaridade dos documentos, os quais deveriam se comportar no sentido de observar o cumprimento do disclosure requerido pelas normas internacionais. Contudo, é importante salientar que a qualidade da informação contábil via notas explicativas pode ser comprometida também por falhas quanto ao julgamento profissional dos preparadores, motivados pelas inúmeras exigências de divulgação requeridas pelos órgãos normatizadores.

Por esse motivo, os órgãos normatizadores internacionais como o European Financial Reporting Advisory Group [EFRAG] (2012), a European Securities and Markets Authority [ESMA], (2015) e o International Accounting Standards Board [IASB], (2013) iniciaram debates e publicaram documentos de discussão, num esforço para controlar a extensão das divulgações de relatórios financeiros e aumentar a sua qualidade. No Brasil, o Comitê de Pronunciamentos Contábeis (CPC) publicou a orientação técnica OCPC 07 [CPC], (2014), com o objetivo de auxiliar na divulgação das demonstrações contábeis e, principalmente, das notas explicativas, que não possuem estrutura rígida de apresentação.

Nesse contexto, procurou-se responder o seguinte problema de pesquisa: Qual é a relação entre a forma de apresentação das notas explicativas e o 
nível de disclosure nas companhias brasileiras, considerando-se as recomendações contidas na OCPC 07 ?

Diante dessa discussão, o estudo tem como objetivo principal investigar a relação entre o nível de disclosure e a forma de apresentação das notas explicativas nas companhias brasileiras, considerando as recomendações contidas na OCPC 07.

Dessa forma, o estudo se justifica pela contribuição sobre o impacto da forma de apresentação das notas explicativas no atendimento ao disclosure requerido pelas normas contábeis internacionais. A qualidade desse documento acaba sendo importante no contexto analisado, por se tratar do principal canal de comunicação e esclarecimento entre empresas e partes interessadas, auxiliando também na redução da assimetria informacional.

Além disso, os achados desta pesquisa foram úteis para avaliar se as recomendações contidas na OCPC 07, com o objetivo de controlar a extensão do disclosure, foram capazes de proporcionar, de fato, um incremento na qualidade informacional das notas explicativas.

Vale ressaltar que o objetivo da OCPC 07 não é, simplesmente, a redução do volume de notas explicativas, mas, sim, uma divulgação com maior potencial explicativo (Carrança, 2015), já que apenas diminuir a extensão das notas explicativas, desconsiderando critérios de relevância e materialidade, pode acarretar uma diminuição nos níveis de qualidade do disclosure.

\section{REFERENCIAL TEÓRICO}

\subsection{Nível de Disclosure e Qualidade da Informação}

O disclosure consiste em apresentar de forma detalhada todas as informações que possibilitem a avaliação da situação patrimonial da empresa e de suas mutações, bem como a realização de inferências sobre resultados futuros (Murcia, 2009), sendo capaz de garantir que os acionistas e outras partes interessadas tenham acesso aos dados econômico-financeiros da empresa de uma forma que os ajude a compreender a natureza do negócio, o seu estágio atual e as suas perspectivas de curto, médio e longo prazo (Martins et al., 2014).

Alhazaimeh, Palaniappan e Almsafir (2014) acrescentam que o disclosure oferece às partes interessadas o conhecimento necessário para reduzir a incerteza, ajudando-as a tomar decisões econômicas e financeiras mais favoráveis. Por outro lado, considerando-se que o disclosure deve alcançar todos os stakeholders, a empresa acaba por incorrer em elevados custos de divulgação, sem garantia de retorno compatível, o que culmina com a realização de uma análise crítica das informações a serem divulgadas (Mapurunga, 2011).

Assim, diante da necessidade de se estabelecer padrões mínimos de divulgação, os órgãos normatizadores atuam no sentido de reduzir a lacuna entre "informados e desinformados" (Healy, \& Palepu, 2001, p. 412). Esse fato está diretamente relacionado ao objetivo de aumentar a qualidade da informação contábil, assegurando que as companhias vêm divulgando adequadamente as informações mínimas requeridas pelas normas vigentes. 
Apesar de as IFRS terem sido determinantes para a harmonização das práticas contábeis de diversos países, não se pode garantir que o cumprimento das normas emitidas pelo International Accounting Standards Board (IASB) ocorre de forma equivalente e eficiente em todos os países que aderiram. O próprio Institute of Chartered Accountants in England and Wales (ICAEW) (2015) já revelou evidências de que, após a adesão às IFRS, a qualidade das informações contábeis é diferente nos diversos países, comprovando que o nível de divulgação pode ser influenciado por diferentes características, legais, econômicas, políticas e institucionais. Nessa linha, verifica-se que as IFRS não se mostram suficientes para determinar a total observância do disclosure (Mapurunga, 2011), de maneira que a empresa faz escolhas contábeis quanto ao que decide divulgar.

De acordo com o IASB (2013), o julgamento profissional por parte dos preparadores acaba sendo deturpado por conta das inúmeras exigências de divulgação estabelecidas pelas entidades normatizadoras, que deveriam emitir orientações que auxiliassem os profissionais da contabilidade a divulgar melhores informações, dando-lhes o suporte necessário ao correto julgamento profissional sobre quais pretendem evidenciar.

Ao analisar a aplicação das IFRS por 183 empresas, a Security Exchange Commission [SEC], (2011) observou que muitas não informam com suficiente precisão ou clareza a sua política de divulgação, a qual tem por objetivo apoiar o entendimento do investidor com relação às demonstrações contábeis. Dessa forma, embora O IASB tenha por objetivo desenvolver um padrão internacionalmente aceitável para o disclosure, as informações baseadas em fatos econômicos podem ainda ser de baixa qualidade, mesmo estando em conformidade com esse padrão contábil.

Assim, ao buscar maior conformidade com o padrão internacional, as empresas vêm elevando o nível de disclosure e, consequentemente, aumentando a qualidade das informações evidenciadas. Contudo, no estudo de Martins (2011) percebe-se um significativo aumento na quantidade das informações evidenciadas pelas empresas, não somente no Brasil, como também em outros países que aderiram às normas internacionais de contabilidade, principalmente devido ao aumento das exigências de divulgação.

Diante dessa problemática, constata-se o surgimento de discussões sobre o fato de as demonstrações contábeis tornarem-se cada dia mais extensas e onerosas, já que com o passar dos anos acaba por ocorrer um excessivo acúmulo de exigências de divulgação, sem, no entanto, haver uma revisão ou remoção da exigência de algumas informações que não são tão úteis, relevantes e materiais para os usuários (Santos, Calixto, \& Bispo, 2019; Santos, Ponte, \& Mapurunga, 2014; Torres, 2012).

Dentre os diversos fatores que contribuem para a divulgação de demasiadas informações não relevantes destacam-se a pouca organização, a má forma de apresentação dos relatórios, a redundância, a divulgação mal orientada e a formação de clichês, além da falta de foco na divulgação dos problemas-chave e nas mudanças ocorridas durante $O$ exercício social pertinente (IASB, 2013). 
Dichev, Graham, Harvey e Rajgopal (2013) esclarecem que quando a empresa detém inteiro entendimento acerca da definição de qualidade informacional, as informações tendem a experimentar significativa melhoria, contribuindo para a divulgação de mais informações relevantes. Nessa linha, os órgãos normatizadores nacionais e internacionais vêm reunindo esforços para estabelecer diretrizes que ajudem os preparadores das demonstrações contábeis a selecionar mais criteriosamente as informações a serem divulgadas, melhorando assim a qualidade informacional, como é o caso do CPC (2014), do EFRAG (2012) e do IASB (2013).

\subsection{OCPC 07}

Considerando toda discussão internacional sobre diretrizes para preparadores garantirem a qualidade da informação contábil divulgada, o CPC emitiu a orientação técnica OCPC 07, para auxiliar na elaboração e na evidenciação das demonstrações contábeis e, principalmente, das notas explicativas, destacando os principais pontos a serem observados na elaboração desses documentos.

Dentre suas recomendações, a OCPC 07 explicita que "nas notas explicativas sobre as bases de elaboração das demonstrações contábeis e as políticas contábeis específicas da entidade não devem ser repetidos os textos dos atos normativos, mas apenas resumidos os aspectos principais relevantes e aplicáveis à entidade" (CPC, 2014, p. 7). Além disso, com relação aos trechos dos normativos transcritos nas demonstrações contábeis fica estabelecido que, segundo a OCPC 07 (CPC, 2014), devem ser feitas apenas menções aos números e nomes dos documentos do CPC, além de um resumo dos aspectos relevantes e especificamente aplicáveis à entidade.

Com relação à orientação para a redação das notas, espera-se que, na medida do possível, não haja repetição de fatos, políticas e informações outras, para não desviar a atenção do usuário (CPC, 2014). Com base no exposto, percebe-se que a OCPC 07 (CPC, 2014) destaca importantes questões sobre a forma de disposição das demonstrações contábeis, especificamente no que tange ao tamanho, à legibilidade e à similaridade das notas explicativas.

\subsection{Estudos Empíricos Anteriores e Hipóteses do Estudo}

Santos, Calixto e Bispo (2019) investigaram o impacto da OCPC 07 sobre tamanho, legibilidade e especificidade de notas explicativas nas empresas brasileiras não financeiras listadas na B3 dois anos após o início da vigência da OCPC 07. Os resultados revelaram uma pequena, mas progressiva, redução no tamanho dos documentos, chegando a uma queda de cerca de $10 \%$. O estudo também confirmou que o tamanho das notas explicativas pode ser considerado uma proxy do nível de disclosure da empresa. Além disso, a análise de regressão confirmou uma associação negativa entre o tamanho e os anos de vigência da OCPC 07, corroborando a expectativa de redução do tamanho das notas explicativas em função da nova norma.

Silva, Ponte, De Luca, Santos e Domingos (2018) investigaram os aspectos relacionados à forma de apresentação das notas explicativas de empresas 
brasileiras do setor de alimentos, diante de recomendações de divulgação estabelecidas pela OCPC 07. Foram levantados como aspectos para a forma de disposição desses documentos o tamanho, a legibilidade e a similaridade, constatando-se uma melhoria significante dos documentos analisados após a emissão da OCPC 07 somente no aspecto legibilidade, sob o argumento de que as empresas ainda precisam avançar em outros aspectos relativos à forma de apresentação desses documentos para atender ao que vem sendo preconizado pelas entidades normatizadoras. Diante dos achados, o estudo constatou pouca influência da OCPC 07 sobre a qualidade da informação contábil no tocante a tamanho e similaridade.

Com base nos estudos apresentados, especificamente de Santos, Calixto e Bispo (2019) e Silva et al. (2018), que investigaram aspectos voltados para a forma de disposição das notas explicativas, foram delineadas as seguintes hipóteses de pesquisa:

Hipótese 1 - Após a publicação da OCPC 07, aumentou a qualidade da informação contábil via notas explicativas, sob aspectos como a forma de apresentação dos documentos e o nível de disclosure.

Hipótese 2 - O nível de disclosure das companhias está associado a aspectos como tamanho, legibilidade e similaridade da forma de apresentação das notas explicativas.

\section{METODOLOGIA}

Quanto aos objetivos, esta pesquisa caracteriza-se como descritiva, já que investiga a relação entre a forma das notas explicativas (refletida por aspectos como tamanho, legibilidade e similaridade) e o nível de disclosure. Enquadra-se também, quanto à natureza, como quantitativa, pois analisa dados numéricos por meio de testes estatísticos. $O$ estudo possui ainda caráter documental, haja vista a utilização de dados secundários, extraídos de notas explicativas.

A amostra da pesquisa compreende todas as companhias de capital aberto do subsetor de alimentos processados listadas na $[B]^{3}$ - Brasil, Bolsa e Balcão. Para seleção da amostra, levou-se em conta a representatividade econômica do segmento no contexto nacional (Rigo, Godoy, \& Scarpin, 2016; Tonetto Filho, \& Fregonesi, 2010), além da necessidade de se estudar um conjunto de empresas com características semelhantes, de modo a possibilitar a análise comparativa entre elas. Além disso, segundo relatório divulgado pela Associação Brasileira das Indústrias de Alimentos (ABIA) o setor alimentício obteve um faturamento de R\$ 642 bilhões em 2018, correspondendo a 9,8\% do Produto Interno Bruto (PIB) nacional e emprega cerca de $20 \%$ de todos os trabalhadores atuantes na indústria de transformação (ABIA, 2019).

Vale salientar que este estudo considera que as mudanças ocorridas na forma de disposição das notas explicativas e no disclosure podem ser decorrentes da curva de aprendizagem ao longo dos anos, razão pela qual 
optou-se por considerar todo o período compreendido entre 2010 e 2017, já que 2010 é o ano que a literatura aborda como full IFRS (Santos, 2011; Salem, \& Damak-Saïhi, 2017; Silva et al., 2018; Sousa, Sousa, \& Demonier, 2016) e 2017 o mais recente quanto à disponibilidade dos relatórios financeiros no momento da coleta dos dados. Ao final, foram analisadas 15 diferentes empresas nos oito anos do período considerado, totalizando 106 notas explicativas, conforme demonstrado na Figura 1.

\begin{tabular}{|c|c|c|c|c|c|c|c|c|c|}
\hline & \multicolumn{4}{|c|}{ Antes da OCPC 07} & \multicolumn{5}{|c|}{ Na vigência da OCPC 07} \\
\hline & 2010 & 2011 & 2012 & 2013 & 2014 & 2015 & 2016 & 2017 & Total \\
\hline BIOSEV & $x$ & $x$ & $\checkmark$ & $\checkmark$ & $\checkmark$ & $\checkmark$ & $\checkmark$ & $\checkmark$ & 6 \\
\hline BRF & $\checkmark$ & $\checkmark$ & $\checkmark$ & $\checkmark$ & $\checkmark$ & $\checkmark$ & $\checkmark$ & $\checkmark$ & 8 \\
\hline EXCELSIOR & $\checkmark$ & $\checkmark$ & $\checkmark$ & $\checkmark$ & $\checkmark$ & $\checkmark$ & $\checkmark$ & $\checkmark$ & 8 \\
\hline FORNO DE MINAS & $x$ & $x$ & $x$ & $x$ & $\checkmark$ & $\checkmark$ & $\checkmark$ & $x$ & 3 \\
\hline J. MACEDO & $\checkmark$ & $\checkmark$ & $\checkmark$ & $\checkmark$ & $\checkmark$ & $\checkmark$ & $\checkmark$ & $\checkmark$ & 8 \\
\hline JBS & $\checkmark$ & $\checkmark$ & $\checkmark$ & $\checkmark$ & $\checkmark$ & $\checkmark$ & $\checkmark$ & $\checkmark$ & 8 \\
\hline JOSAPAR & $\checkmark$ & $\checkmark$ & $\checkmark$ & $\checkmark$ & $\checkmark$ & $\checkmark$ & $\checkmark$ & $\checkmark$ & 8 \\
\hline LAEP & $\checkmark$ & $\checkmark$ & $\checkmark$ & $\checkmark$ & $x$ & $x$ & $x$ & $x$ & 4 \\
\hline M. DIAS BRANCO & $\checkmark$ & $\checkmark$ & $\checkmark$ & $\checkmark$ & $\checkmark$ & $\checkmark$ & $\checkmark$ & $\checkmark$ & 8 \\
\hline MARFRIG & $\checkmark$ & $\checkmark$ & $\checkmark$ & $\checkmark$ & $\checkmark$ & $\checkmark$ & $\checkmark$ & $\checkmark$ & 8 \\
\hline MINERVA & $\checkmark$ & $\checkmark$ & $\checkmark$ & $\checkmark$ & $\checkmark$ & $\checkmark$ & $\checkmark$ & $\checkmark$ & 8 \\
\hline MINUPAR & $\checkmark$ & $\checkmark$ & $\checkmark$ & $\checkmark$ & $\checkmark$ & $\checkmark$ & $\checkmark$ & $\checkmark$ & 8 \\
\hline ODERICH & $\checkmark$ & $\checkmark$ & $\checkmark$ & $\checkmark$ & $\checkmark$ & $\checkmark$ & $\checkmark$ & $\checkmark$ & 8 \\
\hline RAÍZEN ENERGIA & $x$ & $x$ & $x$ & $\checkmark$ & $\checkmark$ & $\checkmark$ & $\checkmark$ & $\checkmark$ & 5 \\
\hline SÃO MARTINHO & $\checkmark$ & $\checkmark$ & $\checkmark$ & $\checkmark$ & $\checkmark$ & $\checkmark$ & $\checkmark$ & $\checkmark$ & 8 \\
\hline Total & 12 & 12 & 13 & 14 & 14 & 14 & 14 & 13 & 106 \\
\hline
\end{tabular}

Figura 1 - Divulgação de notas explicativas pelas empresas da amostra

$(\checkmark)$ Notas Explicativas divulgadas; ( $\mathbf{x}$ ) Notas Explicativas não divulgadas.

Fonte: Elaborado pelos autores.

A Figura 1 detalha a janela de estudo definida para esta pesquisa, segregação que possibilita comparar os períodos anterior e posterior ao início de vigência da OCPC 07, identificando possíveis mudanças nas práticas de divulgação das empresas. Nesse sentido, tomou-se como marco o exercício de 2014 (ano em que foi emitida a OCPC 07 e recomendada a adoção de suas diretrizes). A partir disso, as informações foram segregadas em dois períodos distintos, a saber: um anterior (2010-2013) e outro posterior (2014-2017) à edição do referido normativo. Essa separação tem por intuito possibilitar que se avalie se a publicação da OCPC 07 causou alguma mudança nas práticas de divulgação, conforme sinalizaram Santos, Calixto e Bispo (2019) e Silva et al. (2018).

Para fins de avaliação do disclosure das empresas selecionadas, este estudo considerou os mesmos critérios adotados por Silva (2017), que selecionou normas emitidas pelo CPC consideradas materiais no contexto operacional das empresas de alimentos processados. O autor coletou tais informações por meio de um questionário enviado aos analistas de mercado que atuam no segmento de alimentos, chegando às seis normas listadas na Figura 2. 


\begin{tabular}{|c|l|}
\hline $\mathbf{N}^{\circ}$ do $\mathbf{C P C}$ & \multicolumn{1}{|c|}{ Título } \\
\hline 02 & $\begin{array}{l}\text { Efeitos das Mudanças nas Taxas de Câmbio e Conversão de Demonstrações } \\
\text { Contábeis }\end{array}$ \\
\hline 05 & Divulgação Sobre Partes Relacionadas \\
\hline 25 & Provisões, Passivos Contingentes e Ativos Contingentes \\
\hline 27 & Ativo Imobilizado \\
\hline 30 & Receitas \\
\hline 32 & Tributos Sobre o Lucro \\
\hline
\end{tabular}

Figura 2 - Normativos utilizados na construção da métrica de disclosure Fonte: Silva (2017).

No que tange à análise estatística, a presente pesquisa utilizou testes de médias para avaliar possíveis alterações no disclosure e no tamanho, na legibilidade e na similaridade das notas explicativas após a divulgação da OCPC 07. Adicionalmente, por meio de testes de correlação foi possível investigar a existência de relação entre o disclosure e o tamanho, a legibilidade e a similaridade das notas explicativas. Finalmente, com o uso de testes de regressão linear, verificou-se a capacidade explicativa do tamanho, da legibilidade e da similaridade das notas explicativas sobre o disclosure, junto com variáveis de controle levantadas na literatura que anteriormente já apontaram algum tipo de associação com a divulgação contábil.

A Figura 3 mostra de forma detalhada as variáveis utilizadas para cada um dos aspectos avaliados, assim como sua operacionalização e respectiva base teórica.

\begin{tabular}{|c|c|c|c|c|}
\hline & Variável & Sigla & Operacionalização & Base Teórica \\
\hline \multirow{3}{*}{ 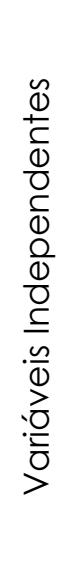 } & $\begin{array}{l}\text { Tamanho das } \\
\text { Notas } \\
\text { Explicativas }\end{array}$ & TAM & Número de palavras do documento. & $\begin{array}{l}\text { Santos, Calixto e } \\
\text { Bispo (2019) e Silva } \\
\text { et al. (2018) }\end{array}$ \\
\hline & $\begin{array}{l}\text { Legibilidade das } \\
\text { Notas } \\
\text { Explicativas }\end{array}$ & FOG & $\begin{array}{l}\text { Índice FOG = } 0.4 \times(\mathrm{MPF})+100 \times(\mathrm{PPC}) \text {, } \\
\text { em que MPF é a média de palavras por } \\
\text { frase e PPC é a porcentagem de } \\
\text { palavras complexas. Assim, quanto } \\
\text { maior é o índice de FOG, mais difícil é a } \\
\text { leitura. }\end{array}$ & $\begin{array}{l}\text { Loughran e } \\
\text { McDonald (2014), } \\
\text { Santos, Calixto e } \\
\text { Bispo (2019) e Silva } \\
\text { et al. (2018) }\end{array}$ \\
\hline & $\begin{array}{l}\text { Similaridade } \\
\text { entre as Notas } \\
\text { Explicativas }\end{array}$ & SIM & $\begin{array}{l}\text { Porcentagem de similaridade das notas } \\
\text { explicativas com documentos na WEB. }\end{array}$ & $\begin{array}{l}\text { Santos, Calixto e } \\
\text { Bispo (2019) e Silva } \\
\text { et al. (2018) }\end{array}$ \\
\hline \multirow{2}{*}{ 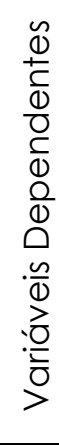 } & $\begin{array}{l}\text { Índice Tolerante } \\
\text { (Nível de } \\
\text { Disclosure) }\end{array}$ & DTO & $\begin{array}{l}\text { Divisão do número de itens divulgados } \\
\text { pelo número de itens requeridos, sendo } \\
\text { o quociente daí resultante subtraído do } \\
\text { número de itens não aplicáveis à } \\
\text { empresa. }\end{array}$ & \multirow{2}{*}{$\begin{array}{l}\text { Santos, Ponte e } \\
\text { Mapurunga (2014) } \\
\text { Silva (2017) e } \\
\text { Umbelino et al. } \\
\text { (2019) }\end{array}$} \\
\hline & $\begin{array}{l}\text { Índice Rigoroso } \\
\text { (Nível de } \\
\text { Disclosure) }\end{array}$ & DRI & $\begin{array}{l}\text { Divisão do número de itens divulgados } \\
\text { pelo número de itens requeridos, sendo } \\
\text { esse quociente subtraído do número de } \\
\text { itens não aplicáveis e também do } \\
\text { número de itens não informados. }\end{array}$ & \\
\hline
\end{tabular}




\begin{tabular}{|c|c|c|c|c|}
\hline & Variável & Sigla & Operacionalização & Base Teórica \\
\hline \multirow{4}{*}{$\begin{array}{l}\frac{0}{0} \\
\frac{1}{1} \\
0 \\
0 \\
0 \\
0 \\
\frac{0}{0} \\
\frac{0}{0} \\
: \frac{0}{0} \\
\frac{0}{7}\end{array}$} & $\begin{array}{l}\text { Auditoria por Big } \\
\text { Four }\end{array}$ & BGF & $\begin{array}{l}\text { Variável dummy que reflete se a } \\
\text { empresa é auditada por Big Four. }\end{array}$ & $\begin{array}{l}\text { Ghoul, Guedhami } \\
\text { e Pittman (2016), } \\
\text { Silva e Costa (2016) } \\
\text { e Silva et al. (2018) }\end{array}$ \\
\hline & $\begin{array}{l}\text { Participação em } \\
\text { Níveis } \\
\text { Diferenciados de } \\
\text { Governança } \\
\text { Corporativa }\end{array}$ & GOV & $\begin{array}{l}\text { Variável dummy que representa a } \\
\text { participação da empresa em algum } \\
\text { dos Níveis Diferenciados de } \\
\text { Governança Corporativa (NDGC). }\end{array}$ & $\begin{array}{l}\text { Barbosa, Scherer, } \\
\text { Scarpin, \& Murcia } \\
\text { (2015), Borges, } \\
\text { Silva, Rech, \& } \\
\text { Carvalho, } \\
\text { Macedo, Oliveira, } \\
\text { Nobre, Brito, \& } \\
\text { Quandt e Silva et } \\
\text { al. (2018) }\end{array}$ \\
\hline & $\begin{array}{l}\text { Negociação em } \\
\text { Mercados } \\
\text { Externos (Emissor } \\
\text { de ADR) } \\
\end{array}$ & ADR & $\begin{array}{l}\text { Variável dummy que representa se as } \\
\text { empresas negociam títulos em } \\
\text { mercados externos. }\end{array}$ & $\begin{array}{l}\text { Santos, Ponte, } \\
\text { Holanda, \& Adachi } \\
\text { (2016) e Silva et al. } \\
(2018)\end{array}$ \\
\hline & $\begin{array}{l}\text { Tempo de } \\
\text { Abertura de } \\
\text { Capital na Bolsa }\end{array}$ & $A B C$ & $\begin{array}{l}\text { Tempo, em anos, correspondente ao } \\
\text { período em que os títulos da empresa } \\
\text { são negociados em bolsa. }\end{array}$ & $\begin{array}{l}\text { Oliveira (2013), } \\
\text { Póvoa e Nakamura } \\
(2014) \text { e Silva et al. } \\
(2018)\end{array}$ \\
\hline
\end{tabular}

Figura 3 - Variáveis da pesquisa

Fonte: Elaborado pelos autores.

Neste estudo, a legibilidade foi mensurada por meio do índice FOG, o qual expressa, segundo Lo, Ramos e Rogo (2017), a relação entre o número de palavras por sentença somada à porcentagem de palavras classificadas como complexas (que possuem mais de três sílabas), sendo esta soma multiplicada pela constante de valor 0,4, obtida como aproximação para o número de anos necessários a fim de se compreender um texto através de educação formal. Segundo os parâmetros deste índice, para que o leitor possua boa compreensibilidade do texto, o índice deve estar entre 10 e 15. Valores maiores podem indicar que o receptor terá dificuldades para compreensão e interpretação, já um índice abaixo de 10 denota um texto de compreensão simples (Gunning, 1952).

Conforme já exposto, a relação entre a forma de apresentação das notas explicativas e o disclosure foi investigada com o auxílio de testes de correlação e regressão linear múltipla, tomando-se por base os achados de Santos, Calixto e Bispo (2019) e Silva et al. (2018). Especificamente para o teste de regressão linear, foram definidos dois modelos econométricos. A Equação 1 refere-se à variável DRI (disclosure rigoroso) a ser explicada e seus possíveis fatores explicativos. Seguindo o mesmo raciocínio, a Equação 2 determina a variável DTO (disclosure tolerante) a ser explicada, juntamente com os mesmos fatores explicativos.

$$
\begin{aligned}
& \text { DRI }=\beta_{0}+\beta_{1} \text { TAM }+\beta_{2} \text { FOG }+\beta_{3} \text { SIM }+\beta_{4} B G F+\beta_{5} \text { GOV }+\beta_{6} \text { ADR } \\
& +\beta_{7} A B C+\varepsilon \\
& \text { DTO }=\beta_{0}+\beta_{1} \text { TAM }+\beta_{2} \text { FOG }+\beta_{3} \text { SIM }+\beta_{4} B G F+\beta_{5} \text { GOV }+\beta_{6} \text { ADR } \\
& +\beta_{7} A B C+\varepsilon
\end{aligned}
$$

(Equação 1)

(Equação 2) 
Recorreu-se ao uso da técnica de regressão linear múltipla, pois esta é aplicada para investigar uma relação determinística entre uma variável dependente e uma ou mais variáveis independentes (Greene, 2012).

A separação dos níveis de disclosure se deu com base na proposta de Santos, Ponte e Mapurunga (2014), os quais perceberam não ser possível supor que uma norma não se aplica a uma empresa simplesmente porque nada é mencionado sobre ela em suas notas explicativas. As autoras afirmam que "por outro lado, não há um requerimento formal nas normas de que as empresas devem indicar de modo explícito nas notas explicativas que uma norma não Ihes é aplicável" (Santos, Ponte, \& Mapurunga, 2014, p. 166). Nesse sentido, como se trata de uma questão de discricionariedade das empresas, este estudo optou pela adoção de dois critérios alternativos para mensurar o cumprimento das exigências de divulgação das IFRS.

\section{RESULTADOS}

\subsection{Apresentação dos Resultados}

Antes da apresentação e discussão dos testes estatísticos aplicados ao estudo, a Tabela 1 expõe a análise inferencial da amostra, que busca propiciar mais familiaridade com os dados em estudo, além de fornecer um maior detalhamento dos dois períodos avaliados na pesquisa, comparando-se o cenário anterior à OCPC 07 com aquele imediatamente posterior ao início de sua vigência.

\section{Tabela 1}

Estatística descritiva

\begin{tabular}{lcccccc}
\hline & $\begin{array}{c}\text { Período em } \\
\text { relação à } \\
\text { OCPC 07 }\end{array}$ & $\mathbf{N}$ & Média & Mediana & $\begin{array}{c}\text { Desvio- } \\
\text { padrão }\end{array}$ & $\begin{array}{c}\text { Erro } \\
\text { Padrão }\end{array}$ \\
\hline \multirow{2}{*}{ DRI } & Antes & 51 & 0.658 & 0.690 & 0.127 & 0.0177 \\
\multirow{2}{*}{ DTO } & Depois & 55 & 0.676 & 0.720 & 0.122 & 0.0165 \\
& Antes & 51 & 0.849 & 0.910 & 0.155 & 0.0217 \\
TAM & Depois & 55 & 0.852 & 0.910 & 0.142 & 0.0191 \\
\multirow{2}{*}{ FOG } & Antes & 51 & 26.194 .529 & 25.613 .000 & 16.225 .540 & 22.720 .301 \\
& Depois & 55 & 26.006 .818 & 23.238 .000 & 16.296 .384 & 21.974 .039 \\
SIM & Antes & 51 & 13.641 & 13.700 & 1.355 & 0.1897 \\
& Depois & 55 & 13.155 & 13.300 & 1.074 & 0.1448 \\
\hline & Antes & 51 & 0.487 & 0.480 & 0.212 & 0.0297 \\
\hline
\end{tabular}

Fonte: Elaborada pelos autores.

A partir da análise dos dados apresentados na Tabela 1, verifica-se com relação ao disclosure que em ambos os índices calculados nenhuma das empresas estudadas alcançou a divulgação máxima dos itens estabelecidos. Adicionalmente, pode-se perceber que esses dados apontam para uma possível melhora dos níveis de disclosure após a divulgação da OCPC 07. Seguindo a mesma trajetória, a extensão das notas explicativas parece ser inferior em comparação com o período anterior à OCPC 07, assim como a 
legibilidade, que em uma análise geral apresentou índices menores no período imediatamente posterior ao início de vigência da OCPC 07.

Em sentido contrário, a porcentagem de similaridade entre os documentos aparenta ter aumentado após a emissão da OCPC 07, passando de $48,7 \%$ antes para $59,3 \%$ depois, de acordo com a Tabela 1. Se for confirmado, esse achado pode sinalizar que as empresas vêm contrariando as determinações das entidades normatizadoras no que tange à repetição, nas notas explicativas, de trechos de outros documentos, como normativos, leis ou mesmo outros documentos anteriormente divulgados.

Visando a análise específica do comportamento da legibilidade apresenta-se, por meio da Tabela 2, os valores obtidos por empresa, incluindo as respectivas médias no período anterior e no posterior ao lançamento da OCPC 07.

Tabela 2

Análise da Legibilidade

\begin{tabular}{l|c|c|c|c|c|c|c|c|c|r}
\hline & \multicolumn{4}{|c}{ Antes da OCPC $\mathbf{0 7}$} & \multicolumn{4}{c}{ Depois da OCPC 07 } \\
\cline { 2 - 12 } & $\mathbf{2 0 1 0}$ & $\mathbf{2 0 1 1}$ & $\mathbf{2 0 1 2}$ & $\mathbf{2 0 1 3}$ & Média & $\mathbf{2 0 1 4}$ & $\mathbf{2 0 1 5}$ & $\mathbf{2 0 1 6}$ & $\mathbf{2 0 1 7}$ & Média \\
\hline BIOSEV & - & - & 12,1 & 13,4 & 12,8 & 13,0 & 13,1 & 11,8 & 12,6 & 12,6 \\
\hline BRF & 11,5 & 12,7 & 12,5 & 12,4 & 12,3 & 12,1 & 11,4 & 11,2 & 11,1 & 11,5 \\
\hline EXCELSIOR & 16,3 & 16,8 & 16,6 & 15,8 & 16,4 & 14,9 & 14,1 & 15,2 & 14,8 & 14,8 \\
\hline FORNODEMINAS & - & - & - & - & - & 13,5 & 14,3 & 13,7 & - & 13,8 \\
\hline J.MACEDO & 13,7 & 13,7 & 13,9 & 13,9 & 13,8 & 13,3 & 13,5 & 12,7 & 13,9 & 13,4 \\
\hline JBS & 14,2 & 13,9 & 13,6 & 13,7 & 13,9 & 12,6 & 11,1 & 12,3 & 13,0 & 12,3 \\
\hline JOSAPAR & 11,7 & 12,9 & 12,7 & 13,0 & 12,6 & 13,0 & 13,3 & 13,3 & 13,5 & 13,3 \\
\hline LAEP & 15,0 & 15,1 & 14,8 & 15,1 & 15,0 & - & - & - & - & - \\
\hline M.DIASBRANCO & 14,3 & 14,3 & 14,1 & 14,3 & 14,3 & 13,7 & 13,5 & 13,6 & 13,8 & 13,7 \\
\hline MARFRIG & 11,7 & 12,3 & 12,7 & 12,0 & 12,2 & 13,3 & 12,6 & 13,3 & 13,5 & 13,2 \\
\hline MINERVA & 13,5 & 14,5 & 14,6 & 14,2 & 14,2 & 13,7 & 13,6 & 14,3 & 12,9 & 13,6 \\
\hline MINUPAR & 13,6 & 14,5 & 14,8 & 14,4 & 14,3 & 14,7 & 14,9 & 10,9 & 14,4 & 13,7 \\
\hline ODERICH & 12,7 & 14,3 & 14,3 & 14,0 & 13,8 & 12,6 & 13,8 & 14,8 & 15,0 & 14,1 \\
\hline RAIZEN ENERG & - & - & - & 12,3 & 12,3 & 12,3 & 11,7 & 12,3 & 12,3 & 12,2 \\
\hline SAO MARTINHO & 13,6 & 10,7 & 11,8 & 11,2 & 11,8 & 12,8 & 12,4 & 12,2 & 12,3 & 12,4 \\
\hline
\end{tabular}

Fonte: Elaborada pelos autores.

Com base na Tabela 2, e considerando a classificação de Gunning (1952), verifica-se que no período anterior ao lançamento da orientação havia uma quantidade maior de empresas cujas médias de legibilidade encontravam-se no intervalo entre 10 e 15 pontos, indicando escrita profissional. Apenas duas empresas apresentaram valor acima de 15 pontos, indicando escrita complexa. Já no cenário posterior à OCPC 07 se pode perceber que todas as empresas se mantiveram no intervalo entre 10 e 15 pontos, o que pode indicar que ocorreu melhora da legibilidade. 


\subsection{Análise dos Resultados}

Após concluída a análise descritiva, passou-se à realização dos testes de diferenças entre médias, para constatação das inferências já levantadas. De acordo com o teste de normalidade aplicado, somente a variável indicativa do índice de legibilidade FOG apresentou distribuição normal, para a qual foi aplicado o teste $t$ (Student). Já para as demais variáveis, foi aplicado o teste não-paramétrico de Mann-Whitney. Os resultados são apresentados de forma unificada na Tabela 3.

\section{Tabela 3}

Teste T e de Mann-Whitney para momento pós OCPC 07

\begin{tabular}{|c|c|c|c|c|c|}
\hline & & Statistic & df & $\mathbf{p}$ & \\
\hline \multirow[t]{2}{*}{ DRI } & Student's $†$ & -0.7571 & 104 & 0.451 & \\
\hline & Mann-Whitney U & 1250 & & 0.335 & \\
\hline \multirow[t]{2}{*}{ DTO } & Student's $†$ & -0.1161 & 104 & 0.908 & \\
\hline & Mann-Whitney U & 1328 & & 0.639 & \\
\hline \multirow[t]{2}{*}{ TAM } & Student's † & 0.0594 & 104 & 0.953 & \\
\hline & Mann-Whitney U & 1357 & & 0.776 & \\
\hline \multirow[t]{2}{*}{ FOG } & Student's $†$ & 20.569 & 104 & 0.042 & $(* *)$ \\
\hline & Mann-Whitney U & 1083 & & 0.044 & \\
\hline \multirow[t]{2}{*}{ SIM } & Student's $†$ & -23.776 & 104 & 0.019 & $(* *)$ \\
\hline & Mann-Whitney U & 1069 & & 0.035 & \\
\hline
\end{tabular}

(**) Nível de significância de $5 \%$.

Fonte: Elaborada pelos autores.

Os resultados refletidos pela Tabela 3 demonstram que somente as médias de legibilidade e similaridade entre as notas explicativas são estatisticamente diferentes nos períodos anterior e posterior ao lançamento da OCPC 07, ou seja, após a divulgação da orientação, as notas explicativas das empresas analisadas tornaram-se mais legíveis ao mesmo tempo em que aparentam seguir um padrão que pode estar ligado à divulgação da notamodelo elaboradas pelas empresas de auditoria.

Além disso, mesmo com as intensas orientações das entidades normatizadoras nacionais e internacionais, no sentido de melhorar a divulgação, não se perceberam mudanças estatisticamente significantes que possam ser atribuídas à divulgação da OCPC 07 no Brasil especificamente para as variáveis disclosure e tamanho das notas explicativas. Isso pode evidenciar que as empresas usam as notas explicativas para atender ao disclosure requerido pelas normas, o que as torna mais extensas, mas sem a preocupação em atender ao critério de relevância.

Vale ressaltar que para a concepção desta pesquisa, foram selecionadas na literatura algumas variáveis que, em estudos anteriores sobre divulgação contábil, já apresentaram associação com o nível de disclosure. Essas variáveis relacionam-se com a participação das empresas em segmentos especiais de governança corporativa, na auditoria por Big Four e na negociação de ADRs. $O$ estudo teve como intenção a validação desses achados no contexto das 
empresas pesquisadas, verificando-se a existência de diferenças estatisticamente significantes nos níveis de disclosure, os quais são apresentados na Tabela 4.

\section{Tabela 4}

Teste de Mann-Whitney (Disclosure x Variáveis de Controle)

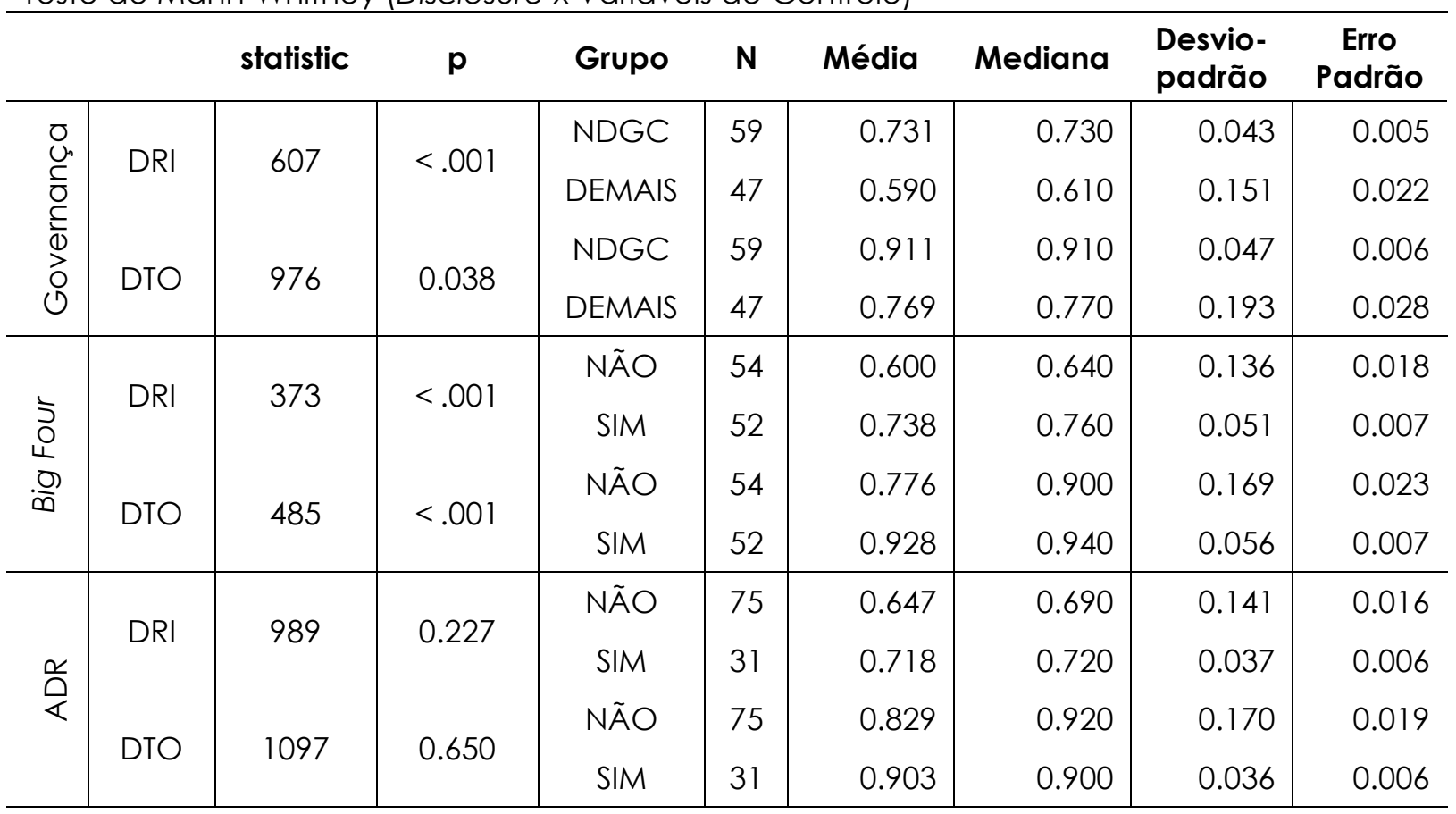

Fonte: Elaborada pelos autores.

Os dados da Tabela 4 demonstram que no setor de alimentos o nível de disclosure tende a ser maior em empresas participantes dos níveis diferenciados de governança corporativa (médias de 0,731 para DRI e 0,911 para DTO), em comparação com aquelas não participantes (médias de 0,590 para DRI e 0,769 para DTO), corroborando os achados de Barbosa et al. (2015), Borges et al. (2016), Macedo et al. (2015) e Silva et al. (2018).

De forma complementar, identificou-se ainda que as companhias auditadas por Big Four, no geral, apresentam altos níveis de disclosure (médias de 0,738 para DRI e 0,928 para DTO), o que se justifica pelo elevado enforcement aplicado por tais empresas devido à cultura de divulgação internacional. Esses achados vão de encontro às conclusões obtidas por Ghoul, Guedhami, Pittman (2016), Silva e Costa (2016) e Silva et al. (2018).

No que se refere à emissão de ADRs, um indicador de internacionalização comumente aplicado em pesquisas das áreas de contabilidade, controladoria e finanças, percebeu-se que, apesar de estudos anteriores sinalizarem que as empresas com papéis negociados em mercados estrangeiros seguem uma trajetória de mais ampla divulgação (Santos, Calixto e Bispo, 2019; Silva et al., 2018), especificamente para as empresas do setor de alimentos listadas na B3 não é possível confirmar tal achado sob bases estatisticamente confiáveis (resultado não significante para DRI e DTO).

Diante dos resultados e conclusões preliminares acerca do comportamento das empresas no que diz respeito à divulgação contábil após o 
advento da OCPC 07 e ao relacionamento existente entre o disclosure e as características das empresas selecionadas, este estudo optou pela realização de testes de correlação para identificar possível aproximação entre tais variáveis, cujo detalhamento encontra-se explicitado na Tabela 5.

Tabela 5

Testes de correlação

\begin{tabular}{|c|c|c|c|c|c|c|c|c|c|c|c|c|}
\hline & & $A B C$ & TAM & & FOG & & SIM & & DRI & & DTO & \\
\hline \multirow[t]{2}{*}{$A B C$} & Spearman'srho & - & -0.646 & & 0.306 & & -0.254 & & -0.626 & & -0.418 & \\
\hline & p-value & - & $<.001$ & $(* *)$ & 0.002 & $(* *)$ & 0.010 & $(* *)$ & $<.001$ & $(* *)$ & $<.001$ & $(* *)$ \\
\hline \multirow{2}{*}{ TAM } & Spearman'srho & & - & & -0.529 & & 0.326 & & 0.554 & & 0.324 & \\
\hline & p-value & & - & & $<.001$ & $(* *)$ & $<.001$ & $(* *)$ & $<.001$ & $(* *)$ & $<.001$ & $(* *)$ \\
\hline \multirow[t]{2}{*}{ FOG } & Pearson's $r$ & & & & - & & -0.018 & & -0.195 & & -0.036 & \\
\hline & p-value & & & & - & & 0.857 & & 0.046 & $(* *)$ & 0.712 & \\
\hline \multirow[t]{2}{*}{ SIM } & Spearman'srho & & & & & & - & & 0.245 & & 0.192 & \\
\hline & p-value & & & & & & - & & 0.011 & $(* *)$ & 0.048 & $(* *)$ \\
\hline \multirow[t]{2}{*}{ DRI } & Spearman'srho & & & & & & & & - & & 0.835 & \\
\hline & p-value & & & & & & & & - & & $<.001$ & $(* *)$ \\
\hline \multirow[t]{2}{*}{ DTO } & Spearman'srho & & & & & & & & & & - & \\
\hline & p-value & & & & & & & & & & - & \\
\hline
\end{tabular}

$(* *)$ Nível de significância de $5 \%$.

Fonte: Elaborada pelos autores.

A Tabela 5 demonstra que, em sentido geral, todas as variáveis levantadas para a forma de apresentação das notas explicativas estão, de alguma maneira, correlacionadas com a divulgação das empresas. Apenas a relação entre o índice de disclosure tolerante e a legibilidade não foi significante, indicando inexistência de correlação. O disclosure tolerante considera que nas empresas que nada mencionaram acerca dos itens de divulgação estes não são aplicáveis, omitindo informações daquilo que não se aplica ao contexto operacional, o que faz com que esse índice acabe assumindo valores menores do que o disclosure rigoroso, critério que pode explicar a discrepância entre os resultados. Assim, verifica-se que, aparentemente, a divulgação de informações mais completas sobre os fatos econômicos que tenham afetado as instituições pode fazer com que as notas explicativas se tornem menos legíveis, prejudicando sua qualidade. Isso significa que há um ganho em volume, mas perde-se em legibilidade dos documentos. Esse achado contrapõe a proposta da OCPC 07 que prega a redução do tamanho dos documentos com a melhora da legibilidade.

Finalmente, com o intuito de complementar a análise dos dados $e$ verificar a capacidade explicativa das variáveis de forma de apresentação das notas explicativas (tamanho, legibilidade e similaridade) e de controle sobre o disclosure, foi realizado teste de regressão linear múltipla, cujos resultados são apresentados na Tabela 6. 
Tabela 6

Teste de regressão linear múltipla

\begin{tabular}{|c|c|c|c|c|c|c|c|c|}
\hline \multirow{2}{*}{ Variável } & \multicolumn{4}{|c|}{ Disclosure Rigoroso } & \multicolumn{4}{|c|}{ Disclosure Tolerante } \\
\hline & Coeficiente & Teste T & \multicolumn{2}{|c|}{ Valor $p$} & Coeficiente & Teste T & \multicolumn{2}{|c|}{ Valor $p$} \\
\hline (Intercept) & 0,819 & 9,761 & 0,000 & $(* *)$ & 0,167 & 1,063 & 0,291 & \\
\hline TAM & 0,000 & 1,022 & 0,309 & & 0,000 & 1,755 & 0,083 & $(* *)$ \\
\hline FOG & $-0,005$ & $-0,972$ & 0,334 & & 0,040 & 3,833 & 0,000 & $(* *)$ \\
\hline SIM & $-0,027$ & $-0,921$ & 0,359 & & 0,117 & 2,293 & 0,024 & $(* *)$ \\
\hline BGF(SIM) & $-0,011$ & $-0,630$ & 0,530 & & 0,116 & 4,269 & 0,000 & $(* *)$ \\
\hline GOV (TRAD) & $-0,110$ & $-2,373$ & 0,020 & $(* *)$ & $-0,019$ & $-0,559$ & 0,577 & \\
\hline ADR(SIM) & $-0,043$ & $-1,356$ & 0,178 & & 0,022 & 0,606 & 0,546 & \\
\hline$A B C$ & $-0,002$ & $-1,043$ & 0,300 & & $-0,003$ & $-2,335$ & 0,022 & $(* *)$ \\
\hline$R^{2}$ & \multicolumn{4}{|c|}{0,34206} & \multicolumn{4}{|c|}{0,36544} \\
\hline $\mathrm{R}^{2}$-Ajustado & \multicolumn{4}{|c|}{0,29306} & \multicolumn{4}{|c|}{0,31818} \\
\hline & \multicolumn{4}{|c|}{102} & \multicolumn{4}{|c|}{102} \\
\hline Teste F (valor p) & \multicolumn{4}{|c|}{$6,94204(0,0000)$} & \multicolumn{4}{|c|}{$7,70806(0,0000)$} \\
\hline
\end{tabular}

$\left({ }^{* *}\right)$ Nível de significância de $5 \%$.

Fonte: Elaborada pelos autores.

Na Tabela 6 nota-se que, conforme os modelos testados por meio de efeitos aleatórios, as variáveis de forma de apresentação das notas explicativas explicam o disclosure tolerante. Esse modelo de extração foi selecionado considerando-se o exposto por Gujarati e Porter (2011) ao afirmar que o modelo de efeitos aleatórios é mais apropriado para amostras aleatórias de uma população, como é o caso daquela utilizada nesta pesquisa. Nesse caso, foi encontrada uma relação positiva e significante para o tamanho ( $p$-value = $0,083)$, a legibilidade ( $p$-value $=0,000)$ e a similaridade $(p$-value $=0,024)$, confirmando a hipótese inicial de existência de relação entre essas duas dimensões da informação contábil.

Esses achados sinalizam que as empresas com maior extensão de notas explicativas apresentam níveis mais altos de disclosure, podendo indicar que o cumprimento da divulgação obrigatória está ligado, necessariamente, com a elaboração de notas explicativas de maior extensão.

Com relação à legibilidade, percebe-se que as empresas aparentemente necessitam de uma linguagem mais complexa para atingir a divulgação pretendida, ou seja, quanto maior o disclosure, menor a legibilidade dos documentos (quanto maior o índice de FOG, mais difícil é a leitura). Ademais, os resultados deste estudo indicaram que, após a emissão da OCPC 07, as notas explicativas revelaram aumento de sua legibilidade, mesmo sem apresentar redução de tamanho, reforçando o debate de que é um grande desafio reduzir o volume de notas, aumentando sua qualidade.

Nota-se também que a similaridade entre as notas explicativas acaba sendo mais elevada em empresas que se preocuparam em fazer maior divulgação, situação que indica o possível uso de um padrão para as notas explicativas já abordado por Santos, Calixto e Bispo (2019), fato que as torna mais semelhantes entre si, mas que ao mesmo tempo possibilita uma divulgação mais assertiva para os itens de divulgação.

De forma complementar, as variáveis explicativas da auditoria por Big Four e do tempo de abertura de capital também se mostraram significantes, corroborando os achados de Santos, Calixto e Bispo (2019) e Silva et al. (2018). 
Neste estudo, especificamente o tempo de abertura de capital das empresas apresentou comportamento contrário ao revelado por Oliveira (2013) e Póvoa e Nakamura (2014), fornecendo evidências de que as empresas com mais tempo de abertura de capital acabam divulgando menos informações. Esse achado pode estar relacionado com a experiência adquirida ao longo do tempo na atuação no mercado de valores mobiliários, conferindo maturidade suficiente para o atendimento satisfatório das exigências com uma divulgação menor em volume.

No que diz respeito à participação das empresas nos níveis diferenciados de governança corporativa, $\mathrm{o}$ índice de disclosure rigoroso apresentou significância negativa para o grupo de companhias não participantes do citado segmento, levando à ratificação dos achados já apresentados na literatura de que há uma maior tendência de cumprimento dos requisitos de divulgação por parte das empresas que adotam políticas de governança corporativa mais rígidas (Barbosa et al., 2015; Borges et al., 2016; Macedo et al., 2015; Silva, et al., 2018).

\section{CONCLUSÕES}

O presente estudo teve como principal objetivo investigar a relação entre a forma de apresentação das notas explicativas e o nível de disclosure nas companhias brasileiras, considerando-se as recomendações da OCPC 07. Para tal, testou duas hipóteses: (1) Após a publicação da OCPC 07, aumentou a qualidade da informação contábil via notas explicativas, sob aspectos como a forma de apresentação dos documentos e o nível de disclosure ; e (2) O nível de disclosure das companhias está associado a aspectos como tamanho, legibilidade e similaridade da forma de apresentação das notas explicativas. Como achados, constatou-se primeiramente que apenas a legibilidade das notas explicativas apresentou melhoras que podem ser atribuídas ao lançamento da OCPC 07. Mesmo diante de tais orientações, verificou-se ainda que esses documentos estão cada dia mais semelhantes entre si, o que sinaliza a adoção de um padrão de divulgação que pode estar sendo ditado pelas firmas de auditoria, já que elas divulgam uma nota-modelo que serve como molde para elaboração pelas empresas. Esses resultados possibilitam a aceitação parcial da Hipótese 1, considerando-se a forma dos documentos e o disclosure.

Através do estudo das variáveis de controle levantadas na literatura e do disclosure, foi possível verificar ainda que as empresas participantes de níveis diferenciados de governança corporativa divulgam mais informações, o que possivelmente está ligado ao fato de que as empresas participantes desse grupo estão sujeitas ao atendimento a práticas de governança corporativa além daquelas já exigidas pelo mercado e pelos órgãos fiscalizadores, gerando um maior volume de informações que devem ser evidenciadas nos relatórios contábeis. Constatou-se ainda que o fato de a empresa ser auditada por uma das Big Four também está positivamente correlacionado com o disclosure, haja vista que essas empresas de auditoria divulgam um modelo de estrutura, servindo para orientar as empresas na preparação de suas próprias notas explicativas, gerando uma padronização das informações divulgadas. Com relação ao tempo de abertura de capital, percebeu-se uma correlação inversa 
com o disclosure, que possivelmente está relacionada ao know-how das empresas, adquirido com a experiência no mercado conquistada no médio e longo prazo, levando à redução do tamanho das notas explicativas, ao se divulgar apenas fatos de utilidade para os stakeholders.

A análise de correlação mostrou a existência de relação entre os aspectos da forma de apresentação das notas explicativas (tamanho, legibilidade e similaridade) e a divulgação contábil. Já o teste de regressão linear sinalizou que o disclosure pode ser explicado positivamente pelo tamanho, legibilidade e similaridade. Dessa forma, percebe-se que, no caso em estudo, a forma das notas explicativas influencia no cumprimento da divulgação obrigatória.

Assim, os achados da pesquisa abrem caminho para novas reflexões acerca do disclosure e sua relação com a forma de apresentação dos documentos contábeis, já que os resultados indicaram relação direta e significante entre o tamanho e a legibilidade das demonstrações contábeis analisadas. Há indícios de que aos poucos a divulgação contábil vem adotando as recomendações contidas na OCPC 07 quando comparados os achados deste estudo com os de Santos, Calixto e Bispo (2019) e Silva et al. (2018).

É importante ressaltar que os resultados aqui apresentados refletem o comportamento de um grupo de empresas com contextos operacionais semelhantes, de tal forma que estender esses achados para outros setores e/ou subsetores requer atenção especial. Propõe-se, então, para pesquisas futuras, a ampliação da amostra analisada, concentrando mais setores econômicos e também um comparativo internacional, de forma que as mesmas hipóteses sejam testadas, verificando se o padrão de divulgação dos achados se mantém.

\section{REFERÊNCIAS}

Alhazaimeh, A., Palaniappan, R., \& Almsafir, M. (2014). The impact of corporate governance and ownership structure on voluntary disclosure in annual reports among listed Jordanian companies. Procedia-Social and Behavioral Sciences, 129(1), 341-348. DOI: 10.1016/j.sbspro.2014.03.686

Associação Brasileira das Indústrias de Alimentos. (2019). Relatório Anual da Associação Brasileira das Indústrias de Alimentos (ABIA). Recuperado em 20 fevereiro, 2019 de : <https://www.abia.org.br/vsn/>.

Barbosa, J. S., Scherer, L. M., Scarpin, J. E., \& Murcia, F. D. (2015). Construção de métrica para avaliação da qualidade da informação contábil sob a ótica de analistas fundamentalistas. Revista de Contabilidade e Organizações, 9(24), 47-55. DOI: 10.11606/rco.v9i24.79534

Barth, M. E., Landsman, W. R., \& Lang, M. H. (2008). International accounting standards and accounting quality. Journal of Accounting Research, 46(3), 467-498. DOI: 10.1111/j.1475-679X.2008.00287.x 
Borges, E. G., Silva, E. C., Rech, I. J., \& Carvalho, L. F. (2016). Efeito da divulgação de informações contábeis sobre o desempenho das ações de empresas que migraram para o nível de governança corporativa Novo Mercado. Revista Eletrônica de Administração e Turismo - ReAT, 8(4), 870889. DOI: 10.15210/REAT.V8|4.6560

Carrança, T. (2015). Comitê espera redução de até 25\% nas notas explicativas de balanços. Valor Econômico. São Paulo. Recuperado em 16 julho, 2020, de http://www.valor.com.br/empresas/ 401 1068/comite-espera-reducao-deate-25-nasnotasexplicativas-de-balancos.

Coelho, C. M. P., Niyama, J. K., \& Rodrigues, J. M. (2011). Análise da qualidade da informação contábil frente a implementação dos IFRS: uma pesquisa baseada nos periódicos internacionais (1999 a 2010). Sociedade, Contabilidade e Gestão, 6(2), 7-20. DOI: 10.21446/scg_ufrj.v6i2.13235

Comitê de Pronunciamentos Contábeis. (2014). OCPC 07 - evidenciação na divulgação dos relatórios contábil-financeiros de propósito geral. Recuperado em 27 dezembro, 2018, de <http://www.cpc.org.br/CPC/ Documentos-Emitidos/Orientacoes/Orientacao?ld=95>

Dichev, I. D., Graham, J.R., Harvey, C., \& Rajgopal, S. (2013). Earnings quality: evidence from the field. Journal of Accounting and Economics, 56(2), 1-33. DOI: 10.1016/j.jacceco.2013.05.004

European Financial Reporting Advisory Group. (2012). Towards a disclosure framework for the notes - discussion paper. Recuperado em 27 dezembro, 2018, de <https://frc.org.uk/Our-Work/Publications/Accounting-andReporting-Policy/Feedback-Statement-Discussion-Paper-Towards-

a/Discussion-Paper-Towards-a-Disclosure-Framework-fo.aspx>.

European Securities and Markets Authority. (2015). Improving the quality of disclosures in the financial statements. Recuperado em 12 fevereiro, 2019, de $<w w w . e s m a . e u r o p a . e u>$.

Ghoul, S., Guedhami, O., \& Pittman, J. (2016). Cross-country evidence on the importance of Big Four auditors to equity pricing: the mediating role of legal institutions. Accounting, Organizations and Society, 54(1), 60-81. DOI: $10.2139 /$ ssrn. 1567524

Greene, W. H. (2012). Econometric Analysis. Pearson Education Limited. (7a ed.). New York: Prentice Hall.

Guay, W., Samuels, D., \& Taylor, D. (2016). Guiding through the fog: financial statement complexity and voluntary disclosure. Journal of Accounting and Economics, 62(2), 234-269. DOI: 10.1016/j.jacceco.2016.09.001

Gujarati, D. N., \& Porter D. C. (2011.) Econometria básica. (5a ed.). Porto Alegre: $\mathrm{AMGH}$ 
Gunning, R. (1952). The Technique of Clear Writing. McGraw-Hill. 36-37.

Healy, P. M., \& Palepu, K. G. (2001). Information asymmetry, corporate disclosure, and the capital markets: a review of the empirical disclosure literature. Journal of Accounting and Economics, 31(1-3), 405-440. DOI: 10.1016/S0165$4101(01) 00018-0$

Hellman, N. (2008). Accounting conservatism under IFRS. Accounting in Europe, 5(2), 71-100. DOl: 10.1080/17449480802510492

Institute of Chartered Accountants in England and Wales. (2015). The effects of mandatory IFRS adoption in the EU: a review of empirical research. Recuperado em 15 janeiro, 2019, de <http://www.icaew.com//media/corporate/files/technical/financial-reporting/information-for-bettermarkets/ifbm/effects-of-mandatory-ifrs-adoption-april-2015-final.ashx?la=en>.

International Accounting Standards Board. (2013). Discussion paper DP/2013/1 a review of the conceptual framework for financial reporting. Recuperado em 23 janeiro, 2019, de <http://www.ifrs.org/projects/work-plan/conceptualframework/comment-letters-projects/dp-review-of-conceptual-framework>.

Klann, I. C., \& Beuren, I. M. (2011). Características de empresas que influenciam o seu disclosure voluntário de indicadores de desempenho. Brazilian Business Review, 8(2), 96-118.

Lima, G. A. S. F. (2007). Utilização da teoria da divulgação para avaliação da relação do nível de disclosure com o custo da dívida das empresas brasileiras. Tese de Doutorado, Universidade de São Paulo, São Paulo, SP, Brasil.

Lo, K., Ramos, F., \& Rogo, R. (2017). Earnings management and annual report readability. Journal of Accounting and Economics, 63(1), 1-25. DOI: 10.1016/j.jacceco.2016.09.002

Loughran, T., \& McDonald, B. (2014). Measuring readability in financial disclosures. The Journal of Finance, 69(4), 1643-1671. DOI: 10.1111/jofi.12162

Macedo, A. F. P., Oliveira, A. M., Nobre, L. N., Brito, S. G., \& Quandt, C. O. (2015). Governança corporativa e evidenciação de capital intelectual em empresas brasileiras. Revista Evidenciação Contábil \& Finanças, 3(1), 18-33. DOI: 10.18405/RECFIN20150102

Mapurunga, P. V. R. (2011). Aderência das firmas ao disclosure requerido pelas normas brasileiras de contabilidade. Dissertação de Mestrado, Universidade Federal do Ceará, Fortaleza, CE, Brasil.

Martins, D. (2011). Adoção de IFRS dobrará notas explicativas do BNDES. Jornal Valor Econômico. Recuperado em 15 fevereiro, 2019, de <http://www.valor.com.br/financas/1067800/adocao-de-ifrs-dobrara-notasexplicativas-no-balanco-do-bndes>. 
Martins, V. G., Oliveira, A. S., Niyama, J. K., \& Diniz, J. A. (2014). Níveis diferenciados de governança corporativa e a qualidade da informação contábil durante o processo de convergência às normas internacionais de contabilidade. Revista Contexto, 14(27), 23-42.

Murcia, F. D. (2009). Fatores determinantes do nível de disclosure voluntário de companhias abertas no Brasil. Tese de Doutorado, Universidade de São Paulo, São Paulo, SP, Brasil.

Oliveira, K. P. S. (2013). Assimetria informacional, qualidade da informação contábil e governança corporativa: características institucionais e organizacionais no mercado de capitais brasileiro. Dissertação de Mestrado, Universidade de Brasília, Universidade Federal da Paraíba, Universidade Federal do Rio Grande do Norte, João Pessoa, PB, Brasil.

Plumlee, M., Brown, D., Hayes, R. M., \& Marshall, R. S. (2015). Voluntary environmental disclosure quality and firm value: further evidence. Journal of Accounting and Public Policy, 34(4), 336-361. DOI: 10.1016/j.jaccpubpol.2015.04.004

Póvoa, A. C. S.; \& Nakamura, W. T. (2014). Homogeneidade versus heterogeneidade da estrutura de dívida: um estudo com dados em painel. Revista Contabilidade \& Finanças, 25(64), 19-32. DOI: 10.1590/S151970772014000100003

Rigo, V. P., Godoy, N., \& Scarpin, J. E. (2016). Comportamento dos custos nas empresas do segmento de alimentos listadas na BM\&FBovespa. ABCustos, 10(2), 20-43. DOI: 10.47179/abcustos.v10i2.236

Salem, R. B., Damaki-Ayadi, S., \& Saïhi, M. (2017). Determinants of full IFRS adoption. Int. J. Managerial and Financial Accounting, 9(2), 105-123. DOI: 10.1504/IJMFA.2017.084776

Santos, E. S. (2011). Full IFRS x lei 11.638 ( $1^{\text {a }}$ fase) $\times$ lei 6.404: impacto esperado nos resultados de 2010 a partir das empresas que se anteciparam. In: Congresso USP de Controladoria e Contabilidade, 11., São Paulo, Anais... São Paulo: USP, 2011.

Santos, E. S., Calixto, L., \& Bispo, M. F. (2019). Impacto da OCPC 07 no enxugamento das notas explicativas das companhias brasileiras. Revista Contabilidade \& Finanças, 30(79), 58-72. DOI: 10.1590/1808-057x201806650

Santos, E. S.; \& Cia, J. N. S. (2009). Impactos esperados da harmonização internacional no lucro das empresas brasileiras, na proxy dos ajustes BRGAAP/USGAAP reportados pelas emissoras de ADRS na Nyse. Revista de Contabilidade e Organizações, 3(6), 57-80. DOI: 10.11606/rco.v3i6.34741

Santos, E. S., Ponte, V. M. R., Holanda, S. S. P., \& Adachi, R. A. (2016). Disclosure under IFRS, legal-accounting traditions and enforcement: comparing ADRs 
issuers on the Nyse with only locally listed firms. In: American Accounting Association Annual Meeting, 100, 2016, New York. Anais... New York, 2016.

Santos, E. S., Ponte, V. M. R., \& Mapurunga, P. V. (2014). Mandatory IFRS adoption in Brazil (2010): index of compliancewith disclosure requirements and explanatory some factorsof firms reporting. Revista Contabilidade \& Finanças, 25(65), 161-176. DOI: 10.1590/S1519-70772014000200006

Securities and Exchange Commission. (2011). Materiality - SEC Staff Accounting Bulletin n. 99. Washington: SEC. Recuperado em 01 fevereiro, 2019, de <https://www.sec.gov/interps/account/sb99.htm>.

Silva, A. A., \& Costa, F. M. (2016). Nível de disclosure x características das pequenas e médias empresas no processo de convergência. Revista de Auditoria, Governança e Contabilidade-RAGC, 4(16), 1-16.

Silva, R. B. (2017). Implicações da OCPC 07 no disclosure e na forma das notas explicativas das demonstrações contábeis. Dissertação de Mestrado, Universidade Federal do Ceará, Fortaleza, CE, Brasil.

Silva, R. B., Ponte, V. M. R., De Luca, M. M. M., SANTOS, E. S., \& Domingos, S. R. M. (2018). Implicações da OCPC 07 sobre a forma das notas explicativas: estudo em empresas de alimentos processados. Revista de Educação e Pesquisa em Contabilidade - Repec, 12(4), 429-449. DOI: 10.17524/repec.v12i4.1848

Sousa, E. F., Sousa, A. F., \& Demonier, G. B. (2016). Adoção das IFRS no Brasil: efeitos no conservadorismo contábil. Revista de Educação e Pesquisa em Contabilidade - Repec, 10(2), 136-147. DOI: 10.17524/repec.v10i2.1290

Takamatsu, R. T., Lamounier, W. M., \& Colauto, R. D. (2008). Impactos da divulgação de prejuízos nos retornos de ações de companhias participantes do Ibovespa. Revista Universo Contábil, 4(1), 46-63. DOI: 10.4270/ruc.20084

Tonetto Filho, V., \& Fregonesi, M. S. F. A. (2010). Análise da variação nos índices de endividamento e liquidez e do nível de divulgação das empresas do setor de alimentos processados com a adoção das normas internacionais. In: Congresso USP de Controladoria e Contabilidade, 14., São Paulo. Anais ... São Paulo: USP.

Torres, F. (2012). Na briga da essência contra a forma prevalece o "medo". São Paulo: Instituto dos Auditores Independentes do Brasil - Ibracon. Recuperado em 15 janeiro. 2019, de <http://www.ibracon.com.br/ibracon/Portugues/ detNoticia.php?.cod $=648>$.

Umbelino, W. L., Ponte, V. M. R., Silva, R. B., \& Lima, M.C. (2019). Disclosure em clubes de futebol: estudo sobre os reflexos da lei do Profut. Revista Evidenciação Contábil \& Finanças, 7(1), 112-132. DOl: ufpb.2318$1001.2019 \mathrm{v} 7 \mathrm{n} 1.38074$ 
CONTRIBUIÇÕES DOS AUTORES

\begin{tabular}{|l|c|c|c|c|}
\hline \multicolumn{1}{|c|}{ Contribuição } & $\begin{array}{c}\text { Régis } \\
\text { Barroso } \\
\text { Silva }\end{array}$ & $\begin{array}{c}\text { Lívia } \\
\text { Arruda } \\
\text { Castro }\end{array}$ & $\begin{array}{c}\text { Sylvia Rejane } \\
\text { Magalhães } \\
\text { Domingos }\end{array}$ & $\begin{array}{c}\text { Vera Maria } \\
\text { Rodrigues } \\
\text { Ponte }\end{array}$ \\
\hline $\begin{array}{l}\text { 1. Idealização e concepção do } \\
\text { assunto e tema da pesquisa }\end{array}$ & $\checkmark$ & & & \\
\hline $\begin{array}{l}\text { 2. Definição do problema de } \\
\text { pesquisa }\end{array}$ & $\checkmark$ & & $\checkmark$ & $\checkmark$ \\
\hline $\begin{array}{l}\text { 3. Desenvolvimento da Plataforma } \\
\text { Teórica }\end{array}$ & $\checkmark$ & & $\checkmark$ & $\checkmark$ \\
\hline $\begin{array}{l}\text { 4. Delineamento da abordagem } \\
\text { metodológica da pesquisa }\end{array}$ & $\checkmark$ & & $\checkmark$ & \\
\hline 5. Coleta de dados & $\checkmark$ & $\checkmark$ & $\checkmark$ & \\
\hline $\begin{array}{l}\text { 6. Análises e interpretações dos } \\
\text { dados coletados }\end{array}$ & & $\checkmark$ & $\checkmark$ & \\
\hline $\begin{array}{l}\text { 7. Conclusões da pesquisa } \\
\text { 8. Revisão crítica do manuscrito }\end{array}$ & $\checkmark$ & $\checkmark$ & $\checkmark$ & $\checkmark$ \\
\hline $\begin{array}{l}\text { 9. Redação final do manuscrito, } \\
\text { conforme as normas estabelecidas } \\
\text { pela Revista. }\end{array}$ & $\checkmark$ & $\checkmark$ & $\checkmark$ & $\checkmark$ \\
\hline 10. Orientação & & & & \\
\hline
\end{tabular}

